\title{
$O$ desafio de revisar aspectos éticos das pesquisas em ciências sociais e humanas: a necessidade de diretrizes específicas
}

| ${ }^{1}$ Iara Coelho Zito Guerriero, ${ }^{2}$ Maria Cecília de Souza Minayo |

Resumo: As diretrizes brasileiras sobre ética em pesquisas com seres humanos são um conjunto de 11 resoluçôes do Conselho Nacional de Saúde (CNS). A Resolução no 196/96 era a mais antiga até 13 de junho de 2013, quando a Resolução 466/12 entrou em vigência, ambas se dirigem a pesquisas em qualquer área do conhecimento. Pesquisadores das ciências sociais e humanas têm encontrado dificuldade na aprovação das suas pesquisas pelo sistema formado pelos Comitês de Ética em Pesquisa (CEP) e pela Comissão Nacional de Ética em Pesquisa (CONEP), ainda que esses projetos não tenham problemas éticos. $\mathrm{O}$ cerne da questão está em que a Resolução no 196/96 considera apenas a pesquisa biomédica e não dialoga com outras tradições de pesquisa. Entretanto, como seu âmbito de abrangência inclui todas as pesquisas com seres humanos, esse sistema a adota por referência e coloca questôes inadequadas, que demonstram desconhecimento das metodologias qualitativas, muito utilizadas nas ciências sociais e humanas. Considerando que a Resolução 466/12 mantém a mesma lógica da Resolução 196/96, este texto discute as raízes históricas da Resolução no 196/96, apresenta algumas dificuldades que esses pesquisadores vêm enfrentando com o sistema CEP-CONEP e aponta as inadequações da definição de pesquisa e dos procedimentos que as diretrizes brasileiras estabelecem para a revisão ética das pesquisas qualitativas em saúde. A Resolução 466/12 coloca possibilidade de uma resolução específica para ciências sociais e humanas que, se acompanhada de capacitação permanente dos membros do Sistema CEP/CONEP, pode melhorar essa situação.

> Palavras-chave: Ética em pesquisa; pesquisa qualitativa em saúde; Comitê de Ética em Pesquisa; Bioética.
1 Instituto de Medicina Tropical de São Paulo, Universidade de São Paulo, Brasil. Endereço eletrônico: iara.guerriero1@ gmail.com

2 Fundação Oswaldo Cruz, Rio de Janeiro, Brasil. Endereço eletrônico: maminayo@terra. com.br

Recebido em: 16/04/2013 Aprovado em: 19/08/2013 


\section{Introdução}

As normas sobre ética em pesquisa com seres humanos sintetizam o que determinada sociedade considera correto e justo para guiar o comportamento dos pesquisadores, num dado momento histórico. Implicam, portanto, uma discussão sobre a ciência e sua inserção social. A produção científica é sempre parcial, provisória, e resulta de decisôes sociais sobre o que e como pesquisar $\mathrm{SHUCH}$, 2010). O mito da ciência neutra, produzida por cientistas isentos, caiu por terra há muito tempo, pelo menos entre pesquisadores das ciências sociais e humanas. A definição sobre o que pesquisar é frequentemente influenciada (e muitas vezes definida) pela disponibilidade de financiamentos, e o pesquisador trabalha a partir de sua inserção social, sendo profundamente marcado pelas questóes de gênero, etnia, condição socioeconômica e, ainda, por seu pertencimento a uma comunidade acadêmica específica.

A discussão sobre ética em pesquisa e sua regulamentação é, portanto, uma discussão política e sempre passível de revisão. Muitas questões éticas estão envolvidas na realização de pesquisas, incluindo a definição de prioridades de financiamento, relação entre pesquisadores e participantes e publicação dos resultados. O desafio é como definir diretrizes éticas aplicáveis às várias comunidades científicas, tanto em termos de princípios quanto de procedimentos. Em meio a essa multiplicidade de questôes, é fundamental identificar o contexto no qual a Resolução no 196/96, do Conselho Nacional de Saúde (CNS) foi elaborada; uma vez que a Resolução 466/12, recém-publicada, mantém a mesma concepção de pesquisa que a Resolução 196/96.

Esse objetivo será cumprido através da análise dos documentos que a fundamentam. Em seguida, discutiremos essa resolução frente à especificidade da pesquisa social, que definimos como a que faz uso de técnicas qualitativas de investigação ou que adota perspectivas analíticas das ciências sociais e humanas (DINIZ, 2010). Utilizamos essa referência ampla como recurso discursivo para contrapô-las ao modelo biomédico. Assim, embora as "ciências sociais e humanas" contemplem uma imensa diversidade de teorias e técnicas, essas diferenças não serão tratadas neste artigo. Da mesma maneira, estamos nos referindo ao sistema formado pelos Comitês de Ética em Pesquisa (CEP) e pela Comissão Nacional de Ética em Pesquisa (CONEP), sistema CEP-CONEP, de maneira geral, uma 
vez que as situações discutidas acontecem em diferentes locais e existem muitas diferenças entre os mais de 600 CEP brasileiros.

Este artigo tem como escopo problematizar a padronização indevida dos procedimentos éticos e para isso desenvolvemos os seguintes tópicos: (1) origens históricas da Resolução CNS no 196/96; (2) problemas lógicos no uso Resolução no 196/96 em relação a pesquisas sociais; (3) principais dificuldades que os pesquisadores sociais encontram; (4) tentativas de revisão da Resolução CNS 196/96; e (5) algumas conclusões.

\section{Origens históricas da Resolução CNS n¹96/96}

No Brasil, o CNS define as diretrizes sobre ética em pesquisa com seres humanos. No momento, o país conta com 11 resoluções sobre essa temática. Até junho de 2013, a mais antiga era a Resolução no 196/96, que se fundamenta nos seguintes documentos internacionais citados em seu preâmbulo: (1) Código de Nuremberg (1947); (2) Declaração de Helsinki (1964, 1975, 1983 e 1989); (3) Propostas de Diretrizes Éticas Internacionais para Pesquisas Biomédicas que envolvem Seres Humanos (CIOMS/OMS- 1982 e 1993); e (4) Diretrizes Internacionais para Revisão Ética de Estudos Epidemiológicos (CIOMS/OMS 1991). Todos esses documentos foram elaborados por instituições médicas, visando regular a pesquisa biomédica e comportamental. Neste texto, focaremos a instituição que elaborou o documento, a definição de pesquisa adotada e seu âmbito de abrangência.

\section{Código de Nuremberg}

Foi elaborado por dois médicos estadunidenses, com base no código de ética médica vigente nos Estados Unidos, para colaborar no julgamento dos crimes cometidos contra a humanidade pelos altos comandantes nazistas, em especial os referentes aos experimentos com seres humanos. O Código de Nuremberg informa que: "O experimento deve ser desenhado e baseado nos resultados de experimentação animal e no conhecimento da história natural da doença ou de outro problema em estudo que a antecipação dos resultados justifique a realização do experimento" (p. 1). Esse código é uma referência constante nos principais documentos internacionais e nacionais sobre ética em pesquisa com seres humanos. Por sua natureza, é um documento único que não passou por nenhuma revisão. 


\section{Declaração de Helsinki}

Foi elaborada pela Associação Médica Mundial para orientar profissionais que trabalham com pesquisa clínica. É citado em todas as pesquisas clínicas biomédicas internacionais e passou por várias revisões, a última em 2008. Entretanto, para elaboração da Resolução no 196/96, foi consultada a versão de 1989, a qual se refere à pesquisa da seguinte maneira: (1) pesquisa biomédica envolvendo sujeitos humanos precisa estar de acordo com princípios científicos usualmente aceitos e ser baseada na experimentação em animal realizada de maneira adequada e na literatura científica; (2) o desenho e o desempenho de cada procedimento experimental envolvendo sujeitos humanos devem ser claramente formulados em protocolo experimental e submetidos para apreciação [...] de um comitê independente (p. 21).

\section{Diretrizes Éticas Internacionais para Pesquisas Biomédicas envolvendo Seres Humanos (CIOMS/OMS - 1982 e 1993)}

O Conselho de Organizaçôes Internacionais das Ciências Médicas (CIOMS), em parceria com a Organização Mundial da Saúde (OMS), elaborou esse documento em 1982 e o revisou em 1993. Sua definição de pesquisa foi adotada na íntegra pela Resolução no 196/96, como veremos a seguir. A versão consultada na Resolução no 196/96 é a de 1993, mas atualmente há uma datada de 2002.

\section{Diretrizes Internacionais para Revisão Ética de Estudos Epidemiológicos - CIOMS/OMS 1991}

Em 1991, o CIOMS, em parceria com a OMS, publicou esse documento que estabelece diretrizes para estudos epidemiológicos. Essa foi a versão consultada quando da elaboração da Resolução no 196/96, também revista pelas instituições que a elaboraram, e há uma versão de 2009. O documento de 1991 aponta que questôes éticas surgem quando valores e interesses entram em conflito, como os do campo da saúde pública, os direitos individuais e as necessidades da comunidade. Propõe que pesquisas que utilizem apenas dados secundários sejam dispensadas da exigência do Termo de Consentimento Livre e Esclarecido (TCLE). Sugere também que nas comunidades em que as decisões são tomadas coletivamente, os líderes possam consentir pela comunidade, desde que garantido o direito individual de se recusar a participar da pesquisa. O documento CIOMS 
1991 considera que um dos benefícios da realização da pesquisa é o retorno de

seus resultados para as autoridades de saúde pública, para as comunidades e para os indivíduos, em linguagem adequada. Essas recomendações não foram explicitamente incluídas na Resolução no 196/96.

\section{Relatório Belmont}

Relatório elaborado por comissão nacional instituída pelo governo dos Estados Unidos para proteção dos sujeitos humanos nas pesquisas biomédicas e comportamentais. O Relatório Belmont define pesquisa como: "atividade desenhada para testar uma hipótese, que permite chegar a conclusões e desenvolver ou contribuir para o conhecimento generalizável expresso, por exemplo, em teorias, princípios e no estabelecimento de relações" (p. 3). Esse relatório exclui pesquisas sociais, pois considera que elas têm outro caráter e deveriam ser avaliadas de forma diferente. Embora não seja citado no preâmbulo, ele foi uma referência para a definição da Resolução no 196/96. Evidência disso é a incorporação dos três princípios propostos: autonomia da pessoa, beneficência e justiça. Além desses três princípios, a Resolução no 196/96 incorpora ainda o princípio da não maleficência. A Resolução 466/12, também incorpora esses quatro princípios, acrescenta o da equidade e deixa em aberto a pertinência de outros princípios.

\section{Resolução no 196/96 (CNS)}

Esta resolução define que: "todo procedimento de qualquer natureza envolvendo o ser humano, cuja aceitação não esteja ainda consagrada na literatura científica, será considerado como pesquisa e, portanto, deverá obedecer às diretrizes da presente resolução. Os procedimentos referidos incluem, entre outros, os de natureza instrumental, ambiental, nutricional, educacional, sociológica, econômica, física, psíquica ou biológica, sejam eles farmacológicos, clínicos ou cirúrgicos e de finalidade preventiva, diagnóstica ou terapêutica (Resolução no 196/96, III. 2).

Essa resolução estendeu seu âmbito de aplicação a pesquisas de todas as áreas do conhecimento. Mas, apesar de pretender-se universal, ela toma por base documentos destinados à pesquisa biomédica, e adota a mesma definição de pesquisa que consta no documento CIOMS/OMS (1993): "pesquisa constitui uma classe de atividades cujo objetivo é desenvolver ou contribuir para o conhecimento generalizável. O conhecimento generalizável consiste em 
teorias, relações ou princípios, ou no acúmulo de informações sobre os quais está baseado e que possa ser corroborado por métodos científicos aceitos de observação e inferência" (Res no 196/96, II.1; CIOMS 1993). Evidencia-se assim a extrapolação de uma definição de pesquisa elaborada por determinada área do conhecimento para todas as outras.

Nesse ponto, a Resolução 466/12 avança, pois sua definição de pesquisa é mais inclusiva: "processo formal e sistemático que visa à produção, ao avanço do conhecimento e/ou à obtenção de respostas para problemas mediante emprego de método científico" (II.12).

Considerando-se que o documento CIOMS (1993) foi elaborado para orientar a aplicação da Declaração de Helsinki, por sua vez organizada para guiar a realização de pesquisas médicas, é surpreendente que essa definição não tenha sido revista quando o escopo da norma foi ampliado para pesquisas de todas as áreas do conhecimento. Isso tem consequências em todas as resoluções do CNS sobre ética em pesquisa com seres humanos, uma vez que tal definição não é revista em nenhuma outra resolução sobre o tema.

Tal situação resulta de um processo histórico, sendo o mais relevante deles o modelo médico hegemônico. Oliveira (2004), por analogia com o conceito de etnocentrismo, considera biocentrismo a aplicação da lógica biomédica às demais áreas do conhecimento. Nas palavras dele, "o biocentrismo da Resolução no 196/96 [...] impõe visão local (biomédica) sobre a prática de pesquisa, ou sobre a ética da prática das pesquisas, como se fosse universal" (p. 33). A hegemonia médica era tão forte no campo de aplicação da Resolução no 196/96, que alguns CEP até a extrapolam, exigindo mais e mais. Trindade e Symanski (2008) relatam o caso de um projeto coordenado por uma psicóloga que ficou em pendência, pois o CEP solicitou que o coordenador do estudo fosse médico.

\section{Problemas lógicos no uso Resolução no 196/96 em relação a pesquisas sociais}

\section{Incongruências da extrapolação dos procedimentos}

O problema central da extrapolação dos procedimentos éticos das pesquisas clínicas e biomédicas para os estudos sociais empíricos, mantido na Resolução $466 / 12$, é considerar que a relação do pesquisador com os participantes da pesquisa se estabelece e se mantém da mesma maneira nas diferentes comunidades 
científicas. No caso das ciências sociais e humanas, em geral, os participantes não

são vistos apenas como objeto de estudo, mas interatuam com os investigadores e sua colaboração tem um caráter de interpretação de primeira ordem, como lembra Schutz (1953), valorizando o senso comum e a reflexão dos sujeitos sobre sua experiência cotidiana. Ou seja, os pesquisadores e seus interlocutores são atores ativos do processo da pesquisa, pois em geral o conhecimento das ciências sociais e humanas é gerado em intersubjetividade. Além disso, o pesquisador costuma entrar no contexto usual dos participantes e os etnógrafos, por exemplo, chegam a morar nas comunidades que estudam. Essa convivência intensa entre equipe de pesquisa e participantes gera um tipo de conhecimento que não ocorre a priori, não podendo, portanto, ser previsto num protocolo de pesquisa. Nesses casos, o pesquisador, como sintetiza Oliveira (2004), cria um padrão de relacionamento que envolve vários tipos de identidade, uma vez que a maneira como ele se coloca no campo modifica seu relacionamento com os interlocutores (Minayo, 2010).

Como reafirma Bevilaqua, "o andamento de uma [pesquisa social empírica] depende a cada passo de microdecisóes relativas a acontecimentos particulares que [...] produzem futuros diferentes (imprevisíveis antes de sua atualização e, portanto, não sujeitos a protocolos rígidos), que se bifurcam em planos específicos de consideração ética” (2010, p. 81). Nesse tipo de estudo, a coleta de dados é em si uma interação social (HEILBORN, 2004), "nada é dado: tudo é construído e construído por alguém que é sujeito, tem interesses e ideologia, sendo importante que o pesquisador explicite a partir de que posição fala e contextualize em que situação conduz seu estudo" (MINAYO, 2010, p. 88). Igualmente, "o próprio objeto é negociado: tanto no plano da interação com os atores, como no plano da construção ou da definição do problema pesquisado" (OLIVEIRA, 2004, p. 34).

Há, portanto, uma diferença central das pesquisas sociais em relação às pesquisas clínicas biomédicas, pois nestas últimas, os procedimentos são definidos pelo pesquisador e realizados por sua equipe no corpo dos que aceitaram participar. As pesquisas clínicas incluem: avaliação clínica e medição dos sinais vitais, como temperatura, pressão, batimentos cardíacos e outros, aos quais frequentemente se acrescenta a coleta de material biológico. Uma vez garantido que a pessoa possui as características necessárias para ser incluída na pesquisa, inicia-se o procedimento experimental. Muitas vezes o estudo se centra na utilização de um novo medicamento: o voluntário é orientado a utilizá-lo da maneira prevista 
na investigação e a comparecer aos retornos médicos para avaliação do efeito do seu uso no corpo (mais avaliaçôes clínicas, mediçôes dos sinais vitais e coleta de material biológico podem ser necessários). A proposta nesse caso é alcançar uma definição objetiva e isenta sobre a segurança e a eficácia (dependendo da fase da pesquisa) de determinado medicamento.

É usual que as pesquisas sobre fármacos adotem procedimentos chamados duplo-cego: o paciente não sabe qual medicamento está efetivamente utilizando ou se está tomando placebo e o médico que o prescreve também não sabe. Frequentemente, alguém designado pelo patrocinador faz a randomização e entrega o medicamento etiquetado no local de dispensação. Trata-se, portanto de uma pesquisa em seres humanos, que faz todos os esforços para excluir a subjetividade do pesquisador e dos participantes, visando à produção de um conhecimento mais objetivo possível. A ideia por traz da despersonalização dessa relação tem vários propósitos, dentre eles o da neutralidade, que obviamente não tem como ser totalmente alcançada, uma vez que sempre existe uma pessoa por trás de cada etapa do experimento. Cabe destacar que tais estudos são necessários para a liberação de comercialização do medicamento no Brasil e no mundo - portanto, diretrizes sobre ética em pesquisa voltadas a eles são absolutamente necessárias.

Em síntese, da definição de pesquisa adotada na Resolução no 196/96 e em suas complementares decorre sua concepção de como se estabelece a relação entre pesquisador e participantes da pesquisa, que está mantida na Resolução $n^{\circ} 466 / 12$. A rigor, a mudança na 466 foi pontual, trocou-se uma definição de pesquisa por outra, sem a devida reflexão sobre suas implicações, que tivesse consequência no texto como um todo. É notório que se toma como referência a pesquisa biomédica, considerada como um modo universal de investigação científica, desconhecendo-se outras racionalidades, abordagens e tradições. Isso vem ocorrendo mesmo quando o documento oficial inclua em sua abrangência tanto as ciências biomédicas e da saúde como as humanas e sociais.

\section{Visão externa do conceito de vulnerabilidade}

Os participantes de uma pesquisa podem ser mais ou menos vulneráveis, dependendo de sua situação ou momento de vida. Qualquer investigador deve ter um relacionamento humano respeitoso com as pessoas com quem interage, 
seja em estudos biomédicos ou sociais. Na pesquisa social empírica, entretanto, a profundidade da relação que o investigador estabelece com seus interlocutores constitui uma condição sine qua non do êxito de seu trabalho. Nesse caso, podemos afirmar que o respeito ao outro é uma questão ética, mas também metodológica, e faz parte da natureza do estudo.

Um desafio importante para qualquer pesquisador e, de forma muito particular, para os que fazem estudos sociais empíricos, é como tratar as pessoas em situação de vulnerabilidade sem retirar delas seu poder de decisão. Uma opção seria relacionar-se com elas de maneira paternalista dentro do pressuposto de que o pesquisador e o sistema CONEP-CEP saberiam o que é melhor para elas. Uma segunda postura é reconhecer nessas pessoas não só sua vulnerabilidade, mas também suas potencialidades, criando espaços de discussão e decisão conjunta. Se escolher a segunda maneira de agir, o pesquisador não trabalhará para proteger seus interlocutores, mas para incluí-los na pesquisa, respeitando sua liberdade e deliberação. Sobre isso argumenta Shuch (2010):

É muito interessante constatar que, exatamente quando a antropologia revê com seriedade seus modos de construção de representações sobre o outro (MARCUS; CLIFFORD, 1986; MARCUS; FISCHER, 1986), problematiza esse outro como resultante de um projeto disciplinar hegemônico colonizador (ABU-LUGHOD, 1991; BHABHA, 1998; SAID, 1989) e renova seu potencial a partir das possibilidades de produção de autoetnografias (RAMOS, 2007) e de interlocução com paraetnógrafos (MARCUS, 2008) sejamos interpelados por procedimentos de regulamentação que impõem uma definição dos sujeitos pesquisados feita, eminentemente, a partir da noção de sua potencial vulnerabilidade. (p. 96).

Ou seja, definir um participante de determinada pesquisa empírica a partir de sua vulnerabilidade retira o foco de suas potencialidades e dificulta o estabelecimento de relações não hierárquicas.

Cabe ressaltar que muitas pesquisas sociais incluem como participantes pessoas que não estão em situação de vulnerabilidade, como secretários da Saúde, políticos, juízes e outros. Mantendo a lógica adotada pela Resolução no 196/96, e agora pela 466/12, de proteção dos vulneráveis, nessas situações quem precisaria ser protegido é o próprio pesquisador. Assim, pressupor que os participantes das pesquisas sociais empíricas são vulneráveis nem sempre resulta numa visão ética adequada. Ao contrário, identificamos questōes diferentes quando o pesquisador tem condição de exercer poder sobre seus interlocutores, e o inverso, quando é o entrevistado que tem mais poder que o pesquisador. 
Imaginemos, por exemplo, o funcionário de um órgão público que faça uma investigação sobre execução orçamentária e descobre corrupção nessa unidade. Ao divulgar os resultados de seu estudo, essa pessoa corre o risco de perder o emprego ou de sofrer represálias. Nesse caso, as normas deveriam prever a proteção do pesquisador que cumpre um mandato ético ao divulgar os dados de seu estudo, ainda que desfavoráveis à instituição ou aos gestores. Tais situações são desafiadoras para pesquisadores e membros do sistema CEP-CONEP, uma vez que colocam em contradição dois itens da Resolução no 196/96, também presentes na Resolução 466/12: o que exige compromisso de divulgar os resultados da pesquisa sejam eles favoráveis ou não, e o compromisso de anonimato dos participantes do estudo, sejam pessoas ou instituições. A nosso ver, o que deve prevalecer é a divulgação de resultados de relevância para a sociedade.

Nessa mesma direção, existem situações em que a divulgação da pesquisa pode provocar dano à reputação de uma instituiçãa. Por que um pesquisador deveria preservar em sigilo os nomes dos hospitais que não estão esterilizando material cirúrgico adequadamente, por exemplo? Nesse caso, a questão não é tornar públicos os nomes dos profissionais ou entrevistados (pois os pesquisadores não podem se confundir com policiais), mas de mostrar o comportamento inadequado que coloca em risco a vida da população usuária e a falta de supervisão competente. Em situações semelhantes a essa, se não forem protegidos os participantes da pesquisa e o próprio pesquisador, existe o risco de se divulgar dados que comprometam as pessoas e salvaguardem práticas institucionais inadequadas. Assim, como todas as questões que dizem respeito à ética, "vulnerabilidade" é um conceito que precisa ser devidamente problematizado em cada pesquisa a cargo dos Comitês de Ética.

\section{Principais dificuldades que os pesquisadores sociais encontram}

Uma das questóes mais plausíveis é que os próprios membros do sistema CEP-CONEP encontrem dificuldades ao revisar as pesquisas sociais, porque nem sempre os termos da Resolução no 196/96, e agora da Res 466/12, são imediatamente aplicáveis à análise das situaçôes concretas. Esse problema tem provocado atrasos ou não aprovação de projetos sociais, mesmo quando não há inadequações éticas (GUERRIERO, 2006; GUERRIERO; DALLARI, 2008). 
Um dos principais problemas é o dos fundamentos científicos. Na ótica das teorias compreensivas, o participante é reconhecido como quem mais sabe sobre sua vida e, portanto, deve ser o primeiro juiz na validação de suas opiniões e representações, levando o pesquisador a tomar decisões conjuntas com ele ao longo da pesquisa. Nas investigações participativas, membros da comunidade podem ser convidados a se incluir na equipe de pesquisa, a partilhar das reflexões e resultados e a serem coautores nas publicações. Portanto, é inadequado tratar uma pesquisa qualitativa com critérios positivistas ou pós-positivistas, para quem o senso comum é considerado ignorância e as decisões de pesquisa são tomadas exclusivamente pelo investigador. É evidente que opostas maneiras de relacionamento entre pesquisadores e participantes têm implicações éticas diferentes.

As consequências dessa inadequação das normas para pesquisadores de ciências sociais e humanas podem ser graves. Há relatos de alunos de graduação que perderam bolsas, alunos de pós-graduação que perderam o prazo para conduzir sua pesquisa (VIEIRA, 2010; PORTO, 2010; LIMA, 2010) e de pesquisadores que perderam financiamentos pela demora ou mesmo não aprovação de seus projetos pelo sistema CEP-CONEP.

As situações narradas por Vieira (2010) e Porto (2010) exemplificam bem essa situação. Vieira relata que o Comitê de Ética impediu a aceitação de seu protocolo porque a folha de rosto estava impressa em duas páginas, quando o CEP só aceita uma. No caso de Porto (2010), houve a exigência de apresentação do questionário, apesar de ela ter informado que na pesquisa utilizaria a técnica de entrevista aberta.

Esses não são casos isolados, infelizmente. Na análise de propostas qualitativas, a demora no aceite e na aprovação está frequentemente associada ao envio de perguntas inadequadas ao pesquisador, entre as quais se incluem: "informe seu cálculo amostral; o número de entrevistados proposto é irrelevante; mande seu desenho de estudo modificado de forma a garantir isenção do pesquisador”. Tais exigências mostram o desconhecimento da especificidade teórica e metodológica da pesquisa social empírica e não contribuem para a tomada de decisão adequada sobre a ética de tal forma de investigação. Aqui, lembramos Geertz (2001), quando afirma que julgar sem compreender é uma ofensa à moral.

Uma das maiores dificuldades que o pesquisador de campo tem ao apresentar seu projeto ao CEP é a exigência por escrito do TCLE assinado por 
cada participante. A seguir, citamos alguns exemplos de situações nas quais consideramos essa exigência inadequada.

\section{Exemplo 1: voluntários da pesquisa e coautores do projeto}

Pesquisa solicitada por uma organização de moradores a determinada universidade para reconstruir a história da localidade e registrá-la em livro de forma acessível à comunidade e à escola local. Os procedimentos desse projeto foram definidos conjuntamente: a comunidade identificou a importância do registro da memória e apontou as pessoas que poderiam prestar informações relevantes porque acompanharam a origem e o desenvolvimento local. Ora, se as decisões sobre a pesquisa foram tomadas conjuntamente, ela, em termos gerais, não coloca riscos aos participantes, uma vez que se tornam atores ativos do processo, são os primeiros juízes do valor do texto e podem avaliar se suas tradições foram adequadamente registradas. A decisão sobre o conteúdo a ser publicado também é conjunta, o que assegura a representatividade das falas e a socialização dos conhecimentos. Seria adequado solicitar que os coautores de um projeto como este assinassem um TCLE? Infelizmente, situações como esta já ocorreram e não são exceções no sistema CEP-CONEP.

\section{Exemplo 2: registros de situações públicas}

Uma professora de educação física propôs uma pesquisa cujos objetivos eram registrar as regras de um jogo indígena e identificar em que medida as regras do futebol foram incorporadas nesse jogo. Planejou assistir às olimpíadas indígenas, observar seu desenvolvimento e anotar as regras usadas nesse evento que ocorre todos os anos. Não seria impossível solicitar TCLE, pois todos os jogadores, nesse caso, estariam presentes. Entretanto, seria adequado solicitar por escrito a permissão para assistir a jogos que ocorrem em público? Novamente, aqui está em questão não o indiscutível respeito aos participantes, mas a adequação e a pertinência do uso da resolução.

A observação de situações públicas para efeitos de pesquisa suscita um debate importante sobre ética. Bevilaqua (2010) identifica três âmbitos nesse particular: (1) uma "ética interna" a cada processo de investigação, que resulta do diálogo entre pesquisador e participantes. Nesse sentido, Adorno (2008, p. 157) afirma que a ética da pesquisa faz "parte da própria pesquisa e das mediações e instâncias 
de contato, relações, experiências vivenciadas e partilhadas com os outros”. (2)

Uma "ética externa", definida no âmbito de uma única comunidade científica que compartilha as mesmas concepções. Nesse sentido, cada comunidade científica deve estabelecer princípios e procedimentos condizentes com os consensos estabelecidos dentro da área. Do código de ética da Associação Brasileira de Antropologia, por exemplo, consta a importância de respeitar os participantes do estudo, representá-los adequadamente nas publicações e colaborar para a justiça social, explicitando-se como se estabelecem e se devem manter relações intersubjetivas em determinado contexto. (3) O terceiro âmbito das "diretrizes de ética em pesquisa” citado por Bevilaqua é proposto pela Resolução no 196/96, que é externa tanto ao processo de cada pesquisa quanto a cada comunidade científica.

É importante que nos perguntemos como se articulam os três âmbitos da ética. Bevilaqua (2010) mostra que muitas vezes existe coerência, mas também há conflito entre as esferas. Ela exemplifica as contradiçôes a partir de uma pesquisa com moradores de uma área invadida, removidos por determinada prefeitura que lhes havia prometido cobrar no máximo $10 \%$ da renda familiar mensal para que comprassem um novo imóvel. $\mathrm{O}$ acordo, porém, não foi cumprido, pois sem aviso prévio, a prefeitura passou a cobrar $20 \%$ da renda dessas famílias.

A pesquisadora acompanhou todo o processo vivenciado pela população, estando presente inclusive nas audiências com a procuradora responsável pelo caso. Embora os moradores soubessem e estivessem de acordo com a realização da investigação, a procuradora não foi informada de que havia um estudo em andamento e que Bevilaqua acompanhava as audiências na condição de pesquisadora. Do ponto de vista da procuradora, ocorria ali uma observação encoberta. Porém, o que motivou Bevilaqua a não informá-la sobre sua identidade foi a lealdade aos moradores, que também não revelaram nada sobre a presença da pesquisadora nas audiências. Na verdade, a procuradora estava sendo observada no exercício de suas funções públicas e numa situação pública. Apesar disso, Bevilaqua (2010) relatou que tomou cuidado de não identificar essa autoridade quando publicou os resultados. Desse exemplo se depreende o seguinte: do ponto de vista dos moradores, a pesquisadora teve uma atitude ética e leal. Entretanto, as normas brasileiras estabelecem que toda pesquisa deve ser conduzida após consentimento livre e esclarecido dos participantes. Assim, a atitude da pesquisadora em relação à procuradora seria considerada eticamente inadequada. 
Tendo em vista que Bevilaqua, na sua relação com os moradores, tinha acesso a informações privilegiadas que diziam respeito aos participantes da pesquisa, parece-nos que a lealdade a esse grupo social seria prioritária. Como recomenda Ferreira (2010, p. 156) "as primeiras normas às quais o antropólogo deve responder eticamente são aquelas que ele construiu dialogicamente com os participantes da pesquisa". Cabe ressaltar ainda que a decisão da investigadora de não se identificar para a procuradora teve, como pano de fundo, seu compromisso com a construção de uma sociedade mais justa: "a percepção de que a produção do conhecimento antropológico não tem um propósito meramente contemplativo é relativamente consensual. Os compromissos intelectuais e éticos dos pesquisadores, sobretudo quando estudam processos de nossa própria sociedade, implicam também um engajamento crítico na promoção de uma sociedade mais justa e solidária” (BEVILAQUA, 2010, p. 86).

\section{Exemplo 3: pesquisa sobre práticas ilegais}

O exemplo é de uma pesquisa sobre motivos de aborto provocado pelas mulheres. O aborto é uma prática ilegal no Brasil. Ao assinar um TCLE aceitando ser incluída na pesquisa, a participante está assumindo que realizou uma prática ilegal. Nessa situação, o TCLE tem uma consequência inversa: não protege a voluntária da pesquisa, pelo contrário, o pesquisador passa a ter em mãos um documento assinado por ela que a incrimina. Em casos assim, parece-nos mais adequado que o investigador entregue à participante uma carta, assinada apenas por ele, na qual explique o projeto de pesquisa e garanta o anonimato do interlocutor. É importante estar explícito nesse documento que o investigador não manterá nenhum registro identificando as pessoas.

\section{Exemplo 4: quando pesquisador}

\section{não sabe previamente qual será seu foco}

Nas pesquisas em psicologia clínica, o pesquisador cria situações para que o participante se manifeste. Entretanto, não é previsível sua reação e ele não tem como informar no TCLE exatamente as perguntas que serão feitas, sobre que assuntos tratará e nem sobre o que publicará. Figueiredo (1995) discute a especificidade dessas pesquisas, ressaltando que o resultado não é procurado pelo pesquisador, é encontrado por ele. Portanto, existem descobertas que só podem 
ser feitas nessa clínica e com essa característica, o que implica que o pesquisador não tem controle da situação e nem seria desejável que tivesse.

A impossibilidade de informar previamente também é vivida por antropólogos que se valem de várias dimensões de sua experiência, uma vez que seu objeto de estudo pode ser redefinido no campo ou depois dele. Oliveira (2004, p. 35) afirma: "não seria nem desejável, do ponto de vista da produção antropológica, que uma definição bem amarrada e conclusiva fosse formulada no início da pesquisa" - isso é claro, pois o trabalho de campo se abre para descobertas que nunca podem ser totalmente previstas a priori.

\section{Revisão da Resolução CNS no 196/96: a Resolução no 466/12}

A Resolução no 466/12 está longe de reconhecer e respeitar as diferentes maneiras de produzir conhecimento científico. Nela não consta nenhuma reflexão sobre a qualidade do relacionamento que se estabelece entre pesquisador e participantes, mantendo-se o mesmo biocentrismo presente no texto da Resolução no 196/96. A falta de reconhecimento e de respeito às diferentes comunidades científicas tem levado as associações nacionais que reúnem pesquisadores das áreas de ciências sociais e humanas a se articularem para reverter a situação. Haja vista a publicação do documento da Associação Nacional de Pesquisa e Pós-Graduação em Psicologia (ANPEPP), com o apoio da Rede Nacional de Ensino e Pesquisa em Terapia Ocupacional (RENETO), e da moção da Associação Brasileira de Antropologia (ABA), que teve apoio da Associação Nacional de Pesquisa e Pós-Graduação em Ciências Sociais (ANPOCS) e da Sociedade Brasileira de Sociologia (SBS), enviada como resposta à consulta pública, no período de revisão do texto da nova resolução. Lamentavelmente, os documentos já publicados e enviados para apreciação da CONEP não foram considerados na elaboração da Resolução no 466/12, mas possivelmente colaboraram para a decisão de elaborar uma resolução específica para ciências sociais e humanas.

\section{Considerações finais}

A Resolução no 196/96 compartilha com os documentos internacionais uma concepção de pesquisa experimental unívoca, que prevê teste de hipótese e visa produzir conhecimento generalizável. Opera com uma maneira de gerar 
conhecimentos na qual os procedimentos são definidos e podem ser descritos pelo pesquisador antes do início da investigação. Os pressupostos dessa forma de fazer ciência não condizem com as abordagens que dependem de uma interação intersubjetiva. As modificações na Resolução 466/12, que revogou a 196/96, não foram profundas o suficiente para alterar essa situação.

No caso da pesquisa em ciências sociais e humanas, o pesquisador não é neutro, assim como, epistemologicamente falando, também não é neutro o pesquisador da área biomédica. Mas no primeiro caso, os investigadores não têm intenção de controlar a natureza nem os outros seres humanos. Há a preocupação de descrever processos e detalhes peculiares de uma comunidade específica sem incluir generalizações. E por compartilhar subjetivamente de todo o processo de investigação, a avaliação da qualidade dos resultados, além de ser feita pela comunidade científica, como é usual em todas as áreas do conhecimento, considera os participantes da pesquisa como seu primeiro juiz de validade.

Consideramos fundamental e imperativo discutir a especificidade da ética nas pesquisas em ciências sociais e humanas. Cremos que os pesquisadores brasileiros e os membros dos Comitês de Ética em Pesquisa já estão maduros para isso e para perceber que as 11 resoluções do Conselho Nacional de Saúde (CNS) vigentes continuam insuficientes e frequentemente inapropriadas para amparar os procedimentos éticos dessa área. Há duas razões para tal conclusão: (1) elas estabelecem procedimentos importantes para pesquisas biomédicas como se fossem universais; e (2) não identificam aspectos éticos específicos ao campo das ciências sociais e humanas e, portanto, não os consideram. Nossa hipótese é que o sistema CEP/CONEP, no caso das pesquisas sociais, tem feito perguntas erradas e que poderiam ser mais bem direcionadas se houvesse abertura para contemplar a diversidade dos campos de conhecimento. Na verdade, o que ocorre no campo conceitual e da aplicação prática das regras éticas não é privilégio apenas dessa formulação setorial. Ela acontece como uma luta de poder no campo da cientificidade das diversas áreas, em que o privilégio é sempre das chamadas ciências ditas naturais.

Portanto, nunca será demais juntar forças para modificar a situação atual. É preciso que as diretrizes brasileiras sobre ética em pesquisa com seres humanos - para que cumpram sua função primordial, que é proteger os participantes, em 
especial nas situações de vulnerabilidade e de evidentes conflitos de interesses -

contemplem as diferentes tradiçóes dos campos de conhecimento e os problemas éticos de cada um. ${ }^{1}$

\section{Referências}

ADORNO, R. Contribuições da etnografia para a Saúde Pública: algumas notas sobre o campo, a pesquisa e as marcas impressas no pesquisador. In: GUERRIERO, I.C.Z.; SCHMIDT, M.L.; ZICKER, F. (Orgs.). Ética nas pesquisas em ciências humanas e sociais na saúde. São Paulo: Hucitec, 2008. p. 148-157.

BEVILAQUA, C.B. Ética e planos de regulamentação da pesquisa: princípios gerais, procedimentos contextuais. In: FLEISCHER, S.; SHUCH, P. (Orgs.). Ética e regulamentação na pesquisa antropológica. Brasília: Letras Vivas, 2010.p.71-90.

BRASIL. Ministério da Saúde. Conselho Nacional de Saúde. Resolução no 196, de 10 de outubro de 1996. Dispóe sobre diretrizes e normas regulamentadoras de pesquisas envolvendo seres humanos [online]. Disponível em <URL:http://conselho.saude.gov.br/ resolucoes/1996/Reso196.doc> Acesso em 6 fev. 2012.

COUNCIL FOR INTERNATIONAL ORGANIZATIONS OF MEDICAL SCIENCES. International Ethical Guidelines for Biomedical Research Involving Human Subjects. Geneva: CIOMS, 1993.

_-___-_. International Guidelines for Ethical Review of Epidemiological Studies [online]. Geneva: CIOMS; 1991. Disponível em: http://www.cioms.ch/publications/ guidelines/1991_texts_of_guidelines.htm Acesso em: 6 fev. 2012.

DINIZ, D. A pesquisa social e os comitês de ética no Brasil. In: FLEISCHER, S.; SHUCH, P. (Orgs.). Ética e regulamentação na pesquisa antropológica. Brasília: Letras Vivas, 2010.p. 183-192.

FERREIRA, L.O. A dimensão ética do diálogo antropológico: aprendendo a conversar com o nativo. In: FLEISCHER, S.; SHUCH, P. (Orgs.). Ética e regulamentação na pesquisa antropológica. Brasília: Letras Vivas, 2010.p.141-158.

FIGUEIREDO, L.C.M. Revisitando as Psicologias: da epistemologia à Ética das práticas e discursos. São Paulo: Educ, 1995.

GEERTZ, C. Nova luz sobre a antropologia. Rio de Janeiro: Jorge Zahar, 2001.

GUERRIERO, I.C.Z.; DALLARI, S.G. The need for adequate ethical guidelines for qualitative health research. Science and Collective Health, Rio de Janeiro, v.13, n.2, p.3003-11, 2008. 
GUERRIERO, I.C.Z. Aspectos éticos das pesquisas qualitativas em saúde. 2006. 230 p. Tese (Doutorado em Saúde Pública)- Faculdade de Saúde Pública, Universidade de São Paulo, São Paulo, 2006.

HEILBORN, M.L. Antropologia e saúde: considerações éticas e conciliação disciplinar. In: VICTORA, C. et al. (Orgs.). Antropologia e ética: o debate atual no Brasil. Niterói: UdUFF, 2004. p.57-63.

LIMA, R. Até onde funciona. Uma breve reflexão sobre a atuação dos comitês de ética em pesquisa no estudo antropológico em saúde. In: FLEISCHER, S.; SHUCH, P. (Orgs.). Ética e regulamentação na pesquisa antropológica. Brasília: Letras Vivas, 2010. p.159-170.

MINAYO, M.C.S. O desafio do conhecimento. Pesquisa qualitativa em saúde. São Paulo: Hucitec, 2010.

OLIVEIRA, L.R.C. Pesquisa em versus pesquisa com seres humanos. In: VICTORA, C. et al. (Orgs.). Antropologia e Ética: debate atual no Brasil. Niterói: UdUFF, 2004. p. 33-44.

PORTO, D. Relato de uma experiência concreta com a perspectiva das ciências da saúde: construindo o antropological blues. In: FLEISCHER, S.; SHUCH, P.(Orgs.). Ética e regulamentação na pesquisa antropológica. Brasília: Letras Vivas, 2010. p. 101-126.

SHUCH, P. Multiplicando perspectivas e construindo verdades parciais. In: FLEISCHER, S.; SHUCH, P. (Orgs.). Ética e regulamentação na pesquisa antropológica. Brasília: Letras Vivas, 2010. p. 91-98.

SCHUTZ, A. Common-sense and Scientific Interpretation in Human Action. In:

Philosophy and Phenomenological Research. New Haven: Yale University Press, 1953. p. 1-38. THE NATIONAL COMMISSION for the Protection on Human Subjects of Biomedical and Behavioral Research. The Belmont Report. Washington, 1979. Disponível em: http:// ohsr.od.nih.gov/guidelines/belmont.html Acesso em: 06 fev. 2012.

TRIALS OF WAR CRIMINALS before the Nuremberg Military Tribunals under Control Council Law No. 10. Nuremberg, October 1946-April 1949. Washington, D.C.: U.S. G.P.O, 1949-1953. Disponível em: http://www.ushmm.org/research/doctors/Nuremberg Code.htm Acesso em: 04 jan. 2006.

TRINDADE, Z.A.; SZYMANSKI, H. O impacto dos Comitês de Ética - CEPs, na atividade de pesquisa em Psicologia. In: GUERRIERO, I.C.Z.; SCHMIDT, M.L.S.; ZICKER, F. (Orgs.). Ética nas pesquisas em ciências humanas e sociais na saúde. São Paulo: Hucitec, 2008. p. 280-303.

VICTORA, C. et al. (Orgs.). Antropologia e ética: o debate atual no Brasil. Niterói: UdUFF, 2004. 
VIEIRA, F.B. Desencontros e descaminhos de uma pesquisa sociológica num hospital público. In: FLEISCHER, S.; SHUCH, P. (Orgs.). Ética e regulamentação na pesquisa antropológica. Brasília: Letras Vivas, 2010.p. 127-140.

WORLD MEDICAL ASSOCIATION. Declaration of Helsinki. Recommendation guiding physicians in biomedical research involving human subjects. Hong Kong, September 1989. Disponível em: http://www.wma.net/en/60about/70history/01declarationHelsinki/ Acesso em: 06 fev. 2012.

\section{Nota}

${ }^{1}$ As autoras não contaram com nenhum financiamento para a elaboração deste texto, que não é resultado de dissertação de mestrado ou tese de doutorado. Não há conflito de interesses. Ambas participaram igualmente de todas as etapas da elaboração do presente artigo. 


\section{Abstract}

\section{The challenge of reviewing ethical aspects of social and human research: the need for specific guidelines}

The Brazilian guidelines on ethics in human research are made up of 11 resolutions of the National Health Council (CNS). The Resolution 196/96 was the oldest one until June 2013, when the Resolution 466/12 was enforced, and was applied to human research in all areas. Researchers from social and human sciences are facing difficulties to have their projects approved by the system made up of the Committees on Ethics in Research (CEP) and the National Commission on Ethics in Research (CONEP), even when these projects have no ethical problems. The key question is that the Resolution 196/96, and Resolution 466/12, considers only the biomedical research and does not dialogue with other research traditions. However, because its scope is all human research, this system based on this resolution asks inadequate questions, that show the lack of knowledge about qualitative research - which is very popular among social and human research. Considering that Resolution 466/12 kept the same logic of Resolution 196/96, this paper discusses the historical roots of Resolution 196/96, presents some difficulties that researchers have been facing with CONEP-CEPs system and points out the inadequacy of the research definition and the procedures established by the Brazilian guidelines to the ethical revision of qualitative research. Specific guidelines for social sciences and humanities are necessary, as well as the permanent qualification of the CEP and CONEP members. Although the Resolution 466/12, enforced in June 13, 2013, does not move in this direction, it opens the possibility to have specific resolution to socials and human sciences that, if in addition to permanent capacity building of members of the system CEP/CONEP, can improve this situation.

> Key words: research ethics; qualitative health research; Research Ethics Committee; Bioethics. 